\title{
Association of urinary 3-phenoxybenzoic acid levels with self-reported depression symptoms in a rural elderly population in Asan, South Korea
}

\author{
Bokyeong Kim ${ }^{1}$, Ara Jung ${ }^{1}$, Dongmin Yun ${ }^{1}$, Mira Lee ${ }^{1}$, Mee-Ri Lee ${ }^{2}$, Yoon-Hyeong Choi ${ }^{3}$, \\ Yongbae Kim ${ }^{4}$, Choonghee Park ${ }^{5}$, Yun-Chul Hong ${ }^{6}$, Sungroul Kim ${ }^{1}$ \\ ${ }^{1}$ Department of Environmental Health Sciences, Soonchunhyang University, Asan; ${ }^{2}$ Department of Preventive Medicine, Seoul \\ National University College of Medicine, Seoul; ${ }^{3}$ Department of Preventive Medicine, Gacheon University College of Medicine, \\ Incheon; ${ }^{4}$ Department of Preventive Medicine, Soonchunhyang University College of Medicine, Cheonan; ${ }^{5}$ Environmental \\ Health Research Division, National Institute of Environmental Research, Incheon; ${ }^{6}$ Environmental Health Center, Seoul \\ National University College of Medicine, Seoul, Korea
}

\begin{abstract}
Objectives This study aimed to evaluate the association between presence of depression symptoms and the exposure level to insecticides among aged population in rural area, determined via measured levels of urinary 3-phenoxybenzoic acid (3-PBA), after controlling for socioeconomic confounding factors.

Methods Using a cross-sectional study design, we randomly recruited participants for our study (161 male and 239 female) from rural areas of Asan, Chungnam, Korea. Environmental risk factor exposure was assessed using a questionnaire, and gas chromatography-mass spectrometry was used to analyze urinary 3-PBA levels. We used a logistic regression analysis to assess the association of urinary 3-PBA levels with the presence of self-reported depression symptoms.

Results After controlling for creatinine levels, the median (interquartile range) concentration of 3-PBA was approximately 1.5 times $(p<0.05)$ higher among female $(1.54$ [0.90 to 2.35]) $\mu \mathrm{g} / \mathrm{g}$ ) than among male (1.06 [0.64 to 1.81] $\mu \mathrm{g} / \mathrm{g}$ ). Our study found that among female participants, the unit increase in 3-PBA levels exhibited a likely positive association (odds ratio, 1.12; 95\% confidence interval, 1.00 to 1.25) with an increased risk of presence of self-reported depression symptoms, after adjusting for socioeconomic insurance type, daily physical condition, marital status, smoking status, and age.

Conclusions Given our finding of a potential association between the presence of selfreported depression symptoms and 3-PBA levels, precautions should be considered to minimize exposure to insecticides and thus protect the health of aged residents in rural areas.
\end{abstract}

Keywords Aging population, Depression, Insecticid, 3-Phenoxybenzoic acid
Correspondence: Sungroul Kim 22 Soonchunhyang-ro, Asan 336-745, Korea Tel: $+82-41-530-1249$

Fax: +82-41-530-1272

E-mail: sungroul.kim@gmail.com

Received: January 7, 2015

Accepted: April 2, 2015

Published online: April 2, 2015

This article is available from: http://e-eht.org/

\section{Introduction}

Globally, increasing numbers of countries are becoming oldage societies [1]; in particular, the South Korean population is aging more rapidly than that of most advanced countries [2].
Countries with rapid progression toward an old-age society tend to face a variety of societal issues such as diminishing human resources and increasing social costs. In particular, depression is more likely to result in suicide in an elderly population than in a younger population $[2,3]$. 
Depression is a common illness among the elderly [4], and geriatric depression has been reported to carry a higher risk of suicide compared with depression in other age groups [3]. This might explain the remarkably extensive research efforts to identify factors that influence depressive symptoms in older people. A literature review of sociomedical studies categorized factors that increase the intensity of depressive symptoms in the elderly and thus increase the prevalence of geriatric depression as economic, physical, or emotional [5]. Some recent domestic and foreign studies have reported an association between the prevalence of geriatric depression and exposure to pesticides [6,7]; however, in South Korea (hereafter Korea) there are not sufficient data to support this hypothesis.

In rural areas, pesticides such as mosquito repellants and agricultural chemicals are common, and most such pesticides are known to contain fast-acting pyrethroids as an active pesticidal ingredient $[8,9]$. Pyrethroid-based pesticides are known to cause neurotoxicity [10]. Urinary 3-phenoxybenzoic acid (3PBA) is a urinary metabolite of the pyrethroid-based chemicals widely used in agricultural or domestic settings and is used as a biomarker. Therefore, from an environmental public health perspective, it is necessary to investigate the association between the level of exposure to pesticidal agents and depressive symptoms related to the prevalence of depression among older people in rural areas, along with socioeconomic and emotional factors. However, such an investigation has yet to be explored at national level. Against this background, the present study was conducted to assess the level of pesticide exposure among an elderly population in a rural area. Specifically, we analyzed urinary 3-PBA levels to determine the association of this biomarker with the incidence of depression assessed using a self-report questionnaire regarding depressive symptom or a depression index.

\section{Materials and Methods}

\section{Study Site and Subjects}

For this study, we recruited 400 older adults ( $\geq 60$ years) who lived in Asan between December 2012 and February 2013 and responded that they had previously worked in agriculture.

\section{Questionnaire Survey Design and Content}

The subjects, who were selected through telephone enquiries based on randomly selected telephone numbers at community centers located in Asan, were visited by surveyors who conducted individual surveys. Five surveyors were trained regarding the survey details to ensure a uniform survey method and skills. This study was approved by the institutional review board of
Seoul National University Hospital, and informed consent was obtained from each subject prior to the survey. The questionnaire comprised items related to demographic (sex and age) and socioeconomic (educational level, income level, marital status, job status, and insurance type) factors, as well as the self-reported absence or presence of depressive symptoms. In addition to this self-report questionnaire, a more objective judgment of depressive symptoms was attempted by extracting the depression index from the short version of the Geriatric Depression Scale, which consists of 15 items (GDS-15). For the GDS-15, scoring is conducted by assigning 1 point to each affirmative response to 10 items and 1 point to each negative response to 5 items; a total depression score $<5$ is considered normal, and scores of 5 to 7 and $\geq 8$ suggest suspected and demonstrated depression, respectively [11-13]. The questionnaire used in this study was also used for the survey on health effects of environmental exposure in the elderly population conducted by the National Institute of Environmental Research, the quality of which has been verified in a number of studies.

\section{Biosample Preparation and 3-Phenoxybenzoic Acid Analysis}

Upon completion of questionnaire survey, urinary samples were taken from 400 participants. Biosamples were harvested in $10-\mathrm{mL}$ conical tubes, stored on ice at the site, and transported to the lab on the same day, where they were stored at $-20^{\circ} \mathrm{C}$ until further transport to the analysis lab. To determine the level of short-term exposure to pyrethroid-based pesticides discharged through urine, a trace element analysis of 3-PBA, a metabolite of the pesticidal active ingredients permethrin and deltamethrin, was performed via gas chromatography-mass spectrometry (Clarus 600T; PerkinElmer, Waltham, MA, USA). The analyzed quantities were used after adjusting for creatinine concentrations. Sample analysis was conducted in a commercial analysis lab. The analyzer had a 3-PBA detection limit of $0.014 \mu \mathrm{g} / \mathrm{L}$ and an accuracy and precision of 108 to 109 and $1.1 \%$, respectively.

\section{Data Analysis}

The collected data were analyzed using SPSS version 20.0 (IBM Corp., Armonk, NY, USA). A p-value < 0.05 was considered to indicate statistical significance. First, a frequency analysis was performed to identify the demographic and socioeconomic characteristics of the subjects, frequency of exposure to pesticides, and presence/absence of depressive symptoms. Second, a logistic regression was used to determine the association between the level of exposure to pesticides, as determined by the urinary metabolite 3-PBA, and the presence/absence of self-reported depressive symptoms experienced in daily life. Third, the associa- 
tion between 3-PBA levels and depression was evaluated using GDS-15 scores instead of the results of the self-reported questionnaire. Finally, we compared and analyzed the results of the GDS-15 screening and self-perception using odds ratios (ORs).

\section{Results}

\section{Demographic Characteristics}

The sex distribution was $59.8 \%$ female $(\mathrm{n}=239)$ and $40.2 \%$ male $(n=161)$. Subjects in the age range of 70 to 79 years (male, $59.6 \%$; female, $48.1 \%$ ) comprised the largest proportion of those surveyed. Regarding educational level, primary school or no schooling was the most frequent (male, $57.1 \%$; female, $89.5 \%$ ). Regarding marital status, whereas $84.5 \%$ of the male subjects answered "married or in a civil union," $63.2 \%$ of the female subjects answered "divorced or widowed." The non-smoker rate was very high, with only a small proportion of the subjects self reported as current smokers (male, 16.8\%; female, $0.42 \%$ ). Agriculture was the main occupation ( $\geq 10$ years) of the majority of the subjects (male, $73.3 \%$; female, $79.5 \%$ ), of whom a fairly high proportion remained engaged in agriculture (male, 50.3\%; female, 32.6\%) at the time of the survey. The most frequent monthly income level was $<500000$ Korean won (KRW) (male, 61.9\%; female, $78.6 \%$ ). Only $56.3 \%$ of male and

Table 1. Demographic and socioeconomic characteristics by sex

\begin{tabular}{|c|c|c|c|}
\hline & Male & Female & $p$-value \\
\hline Total & $161(40.2)$ & 239 (59.8) & \\
\hline $\begin{array}{l}\text { Age (yr) } \\
60-69 \\
70-79 \\
\geq 80\end{array}$ & $\begin{array}{l}36(22.4) \\
96(59.6) \\
29(18.0)\end{array}$ & $\begin{array}{r}47(19.7) \\
115(48.1) \\
77(32.2)\end{array}$ & 0.10 \\
\hline $\begin{array}{l}\text { Education level } \\
\leq \text { Elementary school } \\
\text { Middle school } \\
\text { High school } \\
\geq \text { College }\end{array}$ & $\begin{array}{c}92(57.1) \\
28(17.4) \\
33(20.5) \\
8(5.0)\end{array}$ & $\begin{aligned} & 214(89.5) \\
& 18(7.5) \\
& 7(2.9) \\
& 0(0.0)\end{aligned}$ & $<0.001$ \\
\hline $\begin{array}{l}\text { Marital status } \\
\text { Married } \\
\text { Others }\end{array}$ & $\begin{array}{r}136(84.5) \\
25(15.5)\end{array}$ & $\begin{array}{r}88(36.8) \\
151(63.2)\end{array}$ & $<0.001$ \\
\hline $\begin{array}{l}\text { Smoking status } \\
\text { Smoking } \\
\text { Non-smoking }\end{array}$ & $\begin{array}{r}27(16.8) \\
134(83.2)\end{array}$ & $\begin{array}{c}1(0.4) \\
238(99.6)\end{array}$ & $<0.001$ \\
\hline $\begin{array}{l}\text { Current job: agricultural } \\
\text { Yes } \\
\text { No }\end{array}$ & $\begin{array}{l}81(50.3) \\
80(49.7)\end{array}$ & $\begin{array}{r}78(32.6) \\
161(67.4)\end{array}$ & $<0.001$ \\
\hline $\begin{array}{l}\text { The oldest job: agricultural } \\
\text { Yes } \\
\text { No }\end{array}$ & $\begin{array}{r}118(73.3) \\
43(26.7)\end{array}$ & $\begin{array}{r}190(79.5) \\
49(20.5)\end{array}$ & $<0.001$ \\
\hline $\begin{array}{l}\text { Monthly income (1000 Korean won) } \\
<50 \\
50 \leq-<200 \\
\geq 200\end{array}$ & $\begin{array}{l}78(61.9) \\
23(18.3) \\
20(9.8)\end{array}$ & $\begin{array}{c}132(78.6) \\
30(27.9) \\
6(3.6)\end{array}$ & $<0.001$ \\
\hline $\begin{array}{l}\text { Insurance status } \\
\text { Work } \\
\text { Local } \\
\text { Medicine aid }\end{array}$ & $\begin{array}{l}50(31.7) \\
18(11.4) \\
89(56.3)\end{array}$ & $\begin{array}{c}67(28.3) \\
20(8.4) \\
146(61.6)\end{array}$ & 0.50 \\
\hline $\begin{array}{l}\text { Self-reported depression } \\
\text { Yes } \\
\text { No }\end{array}$ & $\begin{array}{r}129(80.1) \\
32(19.9)\end{array}$ & $\begin{array}{r}161(67.4) \\
78(32.6)\end{array}$ & 0.005 \\
\hline $\begin{array}{l}\text { Depression score } \\
<5 \\
5-7 \\
\geq 8\end{array}$ & $\begin{array}{l}127(78.9) \\
11(6.8) \\
23(14.3)\end{array}$ & $\begin{array}{r}155(64.9) \\
36(15.1) \\
48(20.1)\end{array}$ & 0.007 \\
\hline $\begin{array}{l}\text { Urinary 3-phenoxybenzoic acid } \\
\text { ( } \mu \mathrm{g} / \mathrm{g} \text { creatinine) } \\
\text { (median [interquartile range]) }\end{array}$ & $1.06(0.64,1.81)^{\mathrm{a}}$ & $1.54(0.90,2.35)^{\mathrm{a}}$ & $<0.001$ \\
\hline
\end{tabular}

Values are presented number (\%).

${ }^{\mathrm{a} C}$ Controlled for urinary creatinine concentration. 
$61.6 \%$ of female subjects answered they had health insurance. Excepting age and health insurance status, differences between the sexes were statistically significant $(p<0.001)$ (Table 1$)$.

Although the majority of subjects gave an affirmative answer to the presence of depressive symptoms (male, $80.1 \%$; female, $67.4 \%$ ) during the self-report questionnaire, according to the GDS-15 scores, scores $<5$ points (normal) were most frequent (male, 78.9\%; female, 64.9\%), followed by scores of 5 to 7 (male, $6.8 \%$; female, $15.1 \%$ ) and $\geq 8$ (male, $14.3 \%$; female, $20.1 \%$ ) (Table 1).

\section{Urinary 3-Phenoxybenzoic Acid Level}

The urinary 3-PBA was detected in each urine sample of entire study participants of our study (male, 161; female, 239). The sex-related difference in 3-PBA levels was statistically significant, as the creatinine-adjusted median (interquartile range $[\mathrm{IQR}]$ ) urinary concentrations of 3-PBA were approximately 1.5 times higher in female subjects ( 1.54 [IQR, 0.90 to 2.35$] \mathrm{ug} / \mathrm{g})$ than in male subjects (1.06 [IQR, 0.64 to 1.81$] \mu \mathrm{g} / \mathrm{g})(p<0.05)$.
Urinary 3-Phenoxybenzoic Acid Levels According to the Presence/Absence of Self-reported Depressive Symptoms

A much higher proportion of female than male (32.6\%, 78/239 vs. $19.9 \%, 32 / 161)$ answered they perceived depressive symptoms. Table 2 outlines the association between the self-reported presence/absence of depressive symptoms and 3-PBA concentrations. When analyzed according to demographic and socioeconomic aspects, discrepancies between the self-reported presence/ absence of depressive symptoms and 3-PBA concentrations among male subjects were not statistically significant, whereas among female subjects who reported experiencing depressive symptoms in their daily lives, significantly higher 3-PBA levels were observed in those aged 60 to 69 years $(p=0.010)$ and those with average monthly incomes $\geq 500000 \mathrm{KRW}(p=0.011)$ when compared with the other groups, i.e., those aged 70 or older and those whose monthly income were less than 500000 KRW, respectively. Moreover, a positive association was also observed 5 days after the use of pesticides, but these values were not statistically significant $(p=0.271)$.

Table 2. Urinary 3-phenoxybenzoic acid ( $\mu \mathrm{g} / \mathrm{g}$ creatinine) levels among the elderly participants living in the rural area who reported "currently likely feel depressed" and controls who reported "no feeling of depression"

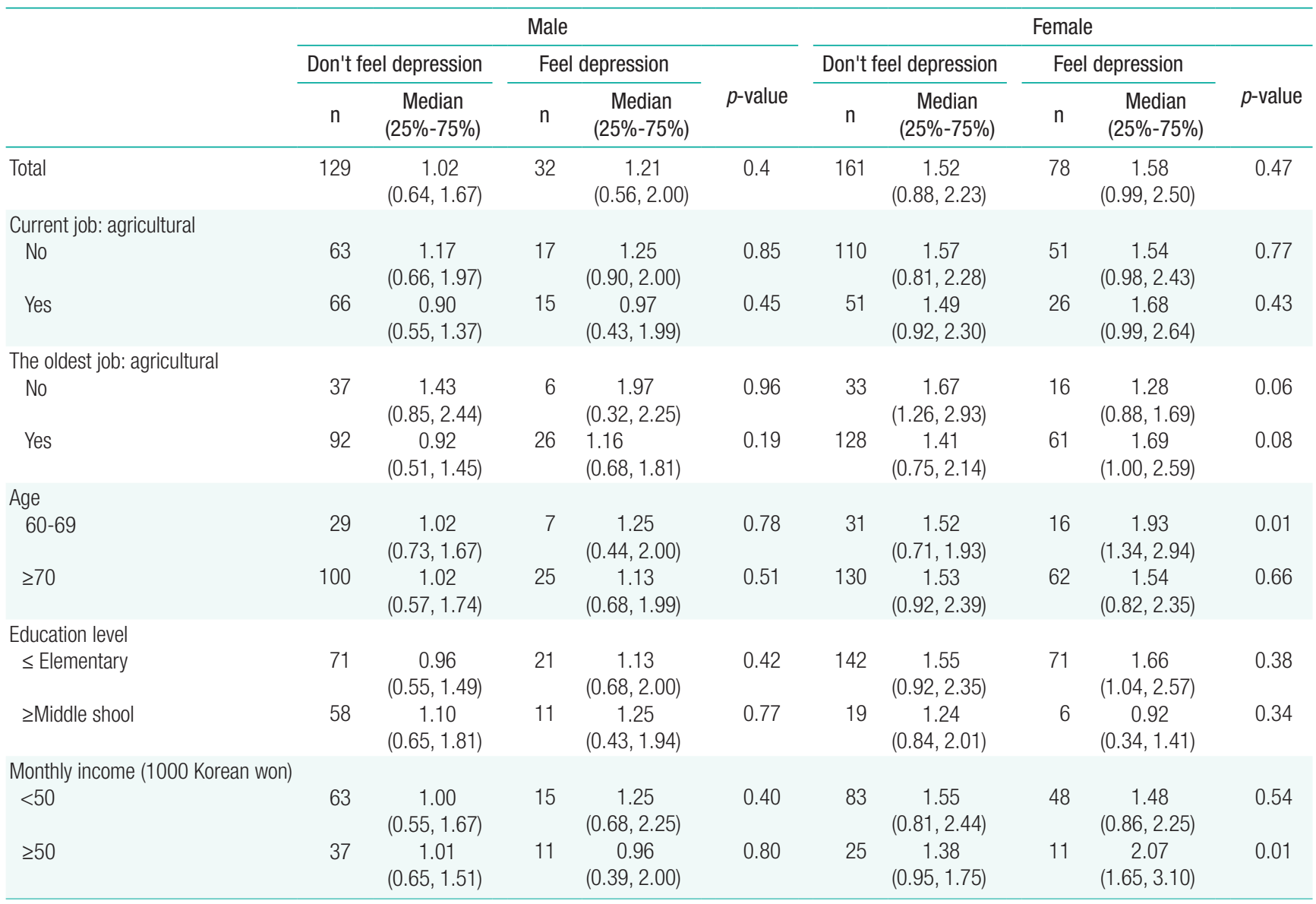




\begin{tabular}{|c|c|c|c|c|c|c|c|c|c|c|}
\hline & \multicolumn{5}{|c|}{ Male } & \multicolumn{5}{|c|}{ Female } \\
\hline & \multicolumn{2}{|c|}{ Don't feel depression } & \multicolumn{2}{|c|}{ Feel depression } & \multirow[b]{2}{*}{$p$-value } & \multicolumn{2}{|c|}{ Don't feel depression } & \multicolumn{2}{|c|}{ Feel depression } & \multirow[b]{2}{*}{$p$-value } \\
\hline & $\mathrm{n}$ & $\begin{array}{c}\text { Median } \\
(25 \%-75 \%)\end{array}$ & $\mathrm{n}$ & $\begin{array}{c}\text { Median } \\
(25 \%-75 \%)\end{array}$ & & $\mathrm{n}$ & $\begin{array}{c}\text { Median } \\
(25 \%-75 \%)\end{array}$ & $\mathrm{n}$ & $\begin{array}{c}\text { Median } \\
(25 \%-75 \%)\end{array}$ & \\
\hline \multicolumn{11}{|l|}{ Smoking status } \\
\hline Non-smoking & 110 & $\begin{array}{c}1.00 \\
(0.56,1.63)\end{array}$ & 24 & $\begin{array}{c}1.41 \\
(0.79,2.26)\end{array}$ & 0.14 & 161 & $\begin{array}{c}1.52 \\
(0.88,2.29)\end{array}$ & 77 & $\begin{array}{c}1.62 \\
(0.99,2.53)\end{array}$ & 0.45 \\
\hline Smoking & 19 & $\begin{array}{c}1.27 \\
(0.90,2.81)\end{array}$ & 8 & $\begin{array}{c}1.05 \\
(0.41,1.21)\end{array}$ & 0.20 & - & - & 1 & 1.28 & \\
\hline \multicolumn{11}{|l|}{ Marriage status } \\
\hline Married & 16 & $\begin{array}{c}0.96 \\
(0.62,2.54)\end{array}$ & 9 & $\begin{array}{c}0.96 \\
(0.44,1.99)\end{array}$ & 0.61 & 99 & $\begin{array}{c}1.54 \\
(0.71,2.36)\end{array}$ & 52 & $\begin{array}{c}1.62 \\
(0.99,2.58)\end{array}$ & 0.39 \\
\hline Others & 113 & $\begin{array}{c}1.02 \\
(0.64,1.63)\end{array}$ & 23 & $\begin{array}{c}1.25 \\
(0.68,2.00)\end{array}$ & 0.27 & 62 & $\begin{array}{c}1.50 \\
(0.93,2.25)\end{array}$ & 26 & $\begin{array}{c}1.58 \\
(1.00,2.12)\end{array}$ & 0.98 \\
\hline \multicolumn{11}{|l|}{ Insurance } \\
\hline Normal (public/local/work) & 58 & $\begin{array}{c}0.93 \\
(0.64,1.80)\end{array}$ & 11 & $\begin{array}{c}1.24 \\
(0.90,1.49)\end{array}$ & 0.43 & 69 & $\begin{array}{c}1.52 \\
(1.08,2.25)\end{array}$ & 22 & $\begin{array}{c}1.58 \\
(1.07,2.57)\end{array}$ & 0.61 \\
\hline Medicaid & 68 & $\begin{array}{c}1.03 \\
(0.57,1.65)\end{array}$ & 21 & $\begin{array}{c}1.18 \\
(0.44,2.00)\end{array}$ & 0.59 & 91 & $\begin{array}{c}1.52 \\
(0.72,2.39)\end{array}$ & 54 & $\begin{array}{c}1.58 \\
(0.98,2.50)\end{array}$ & 0.59 \\
\hline \multicolumn{11}{|l|}{ Residential types } \\
\hline With family & 16 & $\begin{array}{c}0.60 \\
(0.85,1.46)\end{array}$ & 7 & $\begin{array}{c}0.68 \\
(1.13,2.00)\end{array}$ & 0.97 & 56 & $\begin{array}{c}1.74 \\
(1.18,2.57)\end{array}$ & 37 & $\begin{array}{c}1.66 \\
(1.15,2.57)\end{array}$ & 0.24 \\
\hline Others & 110 & $\begin{array}{c}0.68 \\
(1.05,1.74)\end{array}$ & 24 & $\begin{array}{c}0.67 \\
(1.24,1.97)\end{array}$ & 0.64 & 103 & $\begin{array}{c}1.37 \\
(0.77,2.12)\end{array}$ & 39 & $\begin{array}{c}1.58 \\
(0.82,2.50)\end{array}$ & 0.72 \\
\hline \multicolumn{11}{|l|}{ Self-perceived health status } \\
\hline Good & 27 & $\begin{array}{c}1.00 \\
(1.39,1.63)\end{array}$ & 12 & $\begin{array}{c}1.16 \\
(0.52,2.10)\end{array}$ & 0.61 & 88 & $\begin{array}{c}1.61 \\
(0.98,2.29)\end{array}$ & 51 & $\begin{array}{c}1.54 \\
(0.98,2.50)\end{array}$ & 0.84 \\
\hline $\mathrm{Bad}$ & 101 & $\begin{array}{c}1.05 \\
(0.67,1.81)\end{array}$ & 20 & $\begin{array}{c}1.24 \\
(0.67,2.00)\end{array}$ & 0.49 & 73 & $\begin{array}{c}1.40 \\
(0.76,2.30)\end{array}$ & 26 & $\begin{array}{c}1.67 \\
(0.99,2.59)\end{array}$ & 0.23 \\
\hline \multicolumn{11}{|l|}{ Mosquito repellent use } \\
\hline No & 50 & $\begin{array}{c}0.90 \\
(0.52,1.93)\end{array}$ & 6 & $\begin{array}{c}1.21 \\
(0.68,1.81)\end{array}$ & 0.66 & 51 & $\begin{array}{c}1.35 \\
(0.71,-2.35)\end{array}$ & 19 & $\begin{array}{c}1.40 \\
(0.82,2.50)\end{array}$ & 0.79 \\
\hline Yes & 79 & $\begin{array}{c}1.09 \\
(0.67,1.63)\end{array}$ & 26 & $\begin{array}{c}1.19 \\
(0.44,2.00)\end{array}$ & 0.57 & 110 & $\begin{array}{c}1.55 \\
(0.93,2.28)\end{array}$ & 58 & $\begin{array}{c}1.69 \\
(1.07,2.64)\end{array}$ & 0.35 \\
\hline \multicolumn{11}{|l|}{ Insecticide (d) } \\
\hline$<5$ & 64 & $\begin{array}{c}1.13 \\
(0.68,1.82)\end{array}$ & 12 & $\begin{array}{c}1.65 \\
(0.78,2.26)\end{array}$ & 0.33 & 94 & $\begin{array}{c}1.58 \\
(0.77,2.39)\end{array}$ & 48 & $\begin{array}{c}1.57 \\
(0.87,2.22)\end{array}$ & 0.94 \\
\hline$\geq 5$ & 65 & $\begin{array}{c}0.82 \\
(0.48,1.46)\end{array}$ & 20 & $\begin{array}{c}1.07 \\
(0.53,1.72)\end{array}$ & 0.58 & 67 & $\begin{array}{c}1.49 \\
(0.89,2.12)\end{array}$ & 29 & $\begin{array}{c}2.10 \\
(1.07,2.59)\end{array}$ & 0.27 \\
\hline
\end{tabular}

Urinary 3-Phenoxybenzoic Acid Concentration-dependent Association with Self-reported Depressive Symptoms

The concentration dependence of the association between urinary 3-PBA and the self-reported presence/absence of depressive symptoms was evaluated using ORs. Among male subjects, even after adjusting for insurance status, health status, age, smoking/non-smoking, use of mosquito repellants in summer, and use of pesticides, no association was found between an increased biomarker level and the presence/absence of depressive symptoms. Among female subjects, however, after adjusting for the same items, an increase of $1 \mu \mathrm{g} / \mathrm{g}$ in the 3-PBA concentration was found to be concurrent with an approximate $12 \%$ increase in the rate of affirmative answers regarding the presence of depressive symptoms (OR, 1.12; 95\% confidence interval [CI], 1.00 to 1.25 ) (Table 3$)$.
Urinary 3-Phenoxybenzoic Acid Concentration-dependent Association with Depressive Symptoms According to Geriatric Depression Scale-15 Scores

Table 3 outlines the association between differences in GDS15 scores and 3-PBA concentrations. Neither female nor male subjects exhibited evidence of a positive association between changes in the 3-PBA concentration and the presence/absence of depression symptoms according to the GDS-15 scores. Nevertheless, among the aforementioned confounding variables, the groups with self-perceived poor health statuses and that reported using mosquito repellants in summer had higher risks of scores $>5$ points on GDS-15 when compared with the groups with self-perceived good health statuses and that did not report using mosquito repellants in summer, with respective ORs of 1.99 (95\% CI, 1.11 to 3.58 ) and 2.55 (95\% CI, 1.31 to 4.95 ) for 
Table 3. Adjusted odds ratios (95\% confidence interval) for elderly participants who reported "currently likely feel depressed" and classified depression by "GDS-15 score" with unit increase of urinary 3-PBA level

\begin{tabular}{|c|c|c|c|c|c|c|}
\hline & \multicolumn{2}{|c|}{$\begin{array}{l}\text { Reported currently } \\
\text { likely feel depressed }\end{array}$} & \multicolumn{2}{|c|}{$\begin{array}{l}\text { Depression classified } \\
\text { by GDS- } 15 \text { score } \\
\text { (cut-off: } 5 \text { or higher ) }\end{array}$} & \multicolumn{2}{|c|}{$\begin{array}{l}\text { Depression classified } \\
\text { by GDS- } 15 \text { score } \\
\text { (cut-off: } 8 \text { or higher ) }\end{array}$} \\
\hline & Male & Female & Male & Female & Male & Female \\
\hline Urinary 3-PBA ( $\mu \mathrm{g} / \mathrm{g}$ creatinine) & $1.04(0.83,1.32)$ & $1.12(1.00,1.25)^{\star}$ & $0.79(0.53,1.18)$ & $1.00(0.90,1.11)$ & $0.91(0.60,1.37)$ & $1.02(0.90,1.15)$ \\
\hline $\begin{array}{l}\text { Insurance } \\
\text { (Ref: normal) }\end{array}$ & $1.24(0.76,2.03)$ & $1.34(0.97,1.85)$ & $0.77(0.45,1.31)$ & $0.99(0.73,1.35)$ & $0.92(0.51,1.65)$ & $0.92(0.65,1.32)$ \\
\hline $\begin{array}{l}\text { Self-reported health status } \\
\text { (Ref: good) }\end{array}$ & $2.57(1.00,6.60)^{\star}$ & $1.62(0.89,2.93)$ & $4.70(1.72,12.88)^{\star}$ & $1.99(1.11,3.58)^{\star}$ & $4.66(1.64,13.27)^{\star}$ & $2.07(1.02,4.21)^{\star}$ \\
\hline $\begin{array}{l}\text { Marriage } \\
\quad \text { (Ref: married) }\end{array}$ & $1.54(1.06,2.24)^{\star}$ & $1.11(0.91,1.36)$ & $2.11(1.38,3.23)^{*}$ & $1.05(0.86,1.28)$ & $1.45(0.94,2.23)$ & $0.99(0.79,1.25)$ \\
\hline Age & $0.97(0.90,1.04)$ & $0.99(0.95,1.04)$ & $1.07(0.99,1.16)$ & $0.99(0.94,1.03)$ & $1.07(0.99,1.17)$ & $0.99(0.94,1.04)$ \\
\hline Smoking (Ref: No) & $2.09(0.72,6.03)$ & NA & $4.40(1.44,13.48)^{*}$ & NA & $3.54(1.08,11.64)^{\star}$ & NA \\
\hline $\begin{array}{l}\text { Mosquito repellent use } \\
\text { (Ref: No) }\end{array}$ & $4.55(1.51,13.67)^{\star}$ & $1.23(0.65,2.32)$ & $6.83(2.09,22.35)^{\star}$ & $2.55(1.31,4.95)^{\star}$ & $3.98(1.13,14.04)^{*}$ & $1.69(0.78,3.69)$ \\
\hline $\begin{array}{l}\text { Insecticide use } \\
\quad \text { (Ref: <5) }\end{array}$ & $1.62(0.68,3.85)$ & $0.9(0.49,1.63)$ & $1.09(0.43,2.75)$ & $0.75(0.41,1.34)$ & $0.77(0.28,2.10)$ & $0.69(0.34,1.38)$ \\
\hline
\end{tabular}

GDS, Geriatric depression scale; 3-PBA, 3-phenoxybenzoic acid; Ref, reference; NA, not available.

${ }^{*} p<0.05$.

female and 4.70 (95\% CI, 1.72 to 12.88 ) and 6.83 (95\% CI, 2.09 to 22.35 ) for male.

Additionally, when the GDS-15 scores were analyzed using a cut-off threshold of 8 points, which is commonly used as the boundary between normal and suspected depression in Western countries including the US (Table 3), the health status and GDS-15 scores were similarly related (female: 2.07 [95\% CI, 1.02 to 4.21 ], male: 4.66 [95\% CI, 1.64 to 13.27$]$ ). For male, smoking was found to associate strongly with depressive symptoms (GDS-15 score $\geq 5$ or $\geq 8)(p<0.05)$, as was the use of mosquito repellants in summer (GDS-15 score $\geq 5$ or $\geq 8$ ) $(p<0.05)$.

\section{Discussion}

We conducted a survey of the level of exposure to hazardous environmental factors in 400 older adults ( $\geq 60$ years) from a rural area (Asan) and analyzed urinary biomarker levels in relation to pesticide exposure. The sex distribution (male vs. female) of the sample population in this study (60 to 69 years: $43.4 \%$ vs. $56.6 \%$, 70 to 79 years: $44.5 \%$ vs. $54.5 \%$, $\geq 80$ years: $27.4 \%$ vs. $72.6 \%$ ) was similar to that of the entire population of the Asan region according to the 2010 data from Korean Statistical Information Service (60 to 69 years: $46.2 \%$ vs. $53.8 \%, 70$ to 79 years: $41.1 \%$ vs. $58.9 \%$, $\geq 80$ years: $30.2 \%$ vs. $69.8 \%)$. The age criterion for senior citizen status differs among countries. Whereas most advanced countries set this criterion at an age of 65 years, this age does not reflect the situations in all countries. The United Nations proposed the use of 60 years as the age cut- off when referring to older populations [14]. Therefore, this study defined an older population as comprising individuals aged $\geq 60$ years.

Regarding the level of 3-PBA, the biomarker used as an exposure indicator in this study, the median urinary concentrations were higher in female subjects than in male subjects, at 1.54 (IQR, 0.90 to 2.35 ) $\mu \mathrm{g} / \mathrm{g}$ and 1.06 (IQR, 0.64 to 1.81 ) $\mu \mathrm{g} / \mathrm{g}$, respectively. The 2012 data from the National Environmental Health Survey of the Ministry of Environment also revealed higher creatinine-adjusted 3-PBA concentrations in female than in male (male: 1.49 [IQR, 0.80 to 2.83$] \mu \mathrm{g} / \mathrm{g}$; female: 2.20 [IQR, 1.16 to 4.28$] \mu \mathrm{g} / \mathrm{g}$ ) [15]. The absolute concentration levels observed in this study were approximately 7 times lower than those reported in the national data, although the tendency was considered to be identical. Additionally, according to a report from the Ministry of Environment on the National Environmental Health Survey, 3-PBA levels are higher among those aged $\geq 60$ years and in rural residents, and the concentration levels vary depending on the use of mosquito repellants and pesticides, as well as the intake frequency of self-grown agricultural produce [16]. However, given the possibility that the results of this study might have been underestimations, as revealed by the comparison with data from the National Environmental Health Survey, a larger future study that targets the older population in a larger rural area might reveal a stronger association between the 3-PBA level and depressive symptoms.

In the present study, we verified that an increase of $1 \mu \mathrm{g} / \mathrm{g}$ in the 3-PBA concentration coincided with an increase of approximately $12 \%$ in affirmative answers regarding the presence of de- 
pressive symptoms, and this relationship was maintained even after adjusting for confounding variables such as the insurance type and perceived health status (OR, 1.12; 95\% CI, 1.00 to 1.25). In this study, we found that, in female subjects, a $1 \mu \mathrm{g} / \mathrm{g}$ increase in 3-PBA concentration was positively, but not significantly, associated with the increase of the GDS-15 score, which we evaluated as a depression index. However, among male subjects, no association was observed between the increase in the urinary 3-PBA level and the self-reported presence/absence of depression symptoms or GDS-15 scores.

At the international level, an association between the level of pesticide exposure and depression has been reported in farmers even after adjusting for various sociocultural factors.[17,18] According to the report of a study conducted by Beseler et al.[18], 52 (6.0\%) of 872 farmers living in Colorado reported that they had been treated for depression. This study also reported that pesticide poisoning and the experience of depression were interrelated after adjusting for gender, age, and marital status (OR, 2.59; 95\% CI, 1.20 to 5.58) and that the relationship was maintained, albeit to a lesser degree, even after adjusting for health status and economic situation (OR, 2.00; 95\% CI, 0.91 to 4.39). However, as the study by Beseler and colleagues[18] used the Center for Epidemiologic Studies Depression Scale as a depression index and conducted their survey without distinguishing among pesticides, herbicides, and fungicides, those results cannot be directly compared with our study, in which GDS-15 was used as the depression index and 3-PBA was used as biomarker to indicate the level of pesticide exposure.

In a 2010 study of farmers, Mackenzie et al. [19] reported that farmers with a history of pesticide exposure had a higher prevalence of depression than did control subjects ( $46.9 \%$ vs. $6.5 \%$; $\chi^{2}=33.97, p<0.01$ ). Likewise, a 2004 study of farmers conducted by Sanne et al. [20] found correlations between agriculture and depression in both male and female (male: OR, 2.03; 95\% CI, 1.61 to 2.55 , female: OR, 1.68 ; $95 \%$ CI, 1.19 to 2.35 ).

A study conducted in Korea also reported that a large number of socio-epidemiological studies verified the association between depression and social factors such as a low income, bereavement, and low educational level [21]. More recently, a study in which GDS-15 was used as a screening tool for depressive symptoms [22]. among farmers reported that 197 (10.4\%) of 1958 male exhibited depressive symptoms (GDS-15 score $\geq 8$ ) and that an association between occupational pesticide poisoning and depression was apparent even after adjusting for latent confounding variables. In our study, $19.9 \%$ of male and $32.6 \%$ of female reported self-perceived depression, whereas only $6.8 \%$ male and $15.1 \%$ of female had GDS- 15 scores of 5 to 7 points and only $14.3 \%$ of male and $20.1 \%$ of female had scores of $\geq 8$ points. In the 2013 study by Kim et al. [22], similar GDS15 scores $(\geq 8)$ were measured in male as we mentioned above. In our study, however, no association between pesticide exposure and presence of self-reported depressive symptoms was verified in male. Given that, unlike the study by Kim et al. [22] which used survey-based pesticide exposure level, our study used biomarker concentrations as a key determinant. Therefore, a direct comparative analysis between these two studies was limited.

We explored the relationship between depressive symptoms and urinary 3-BPA concentration, which served as a biomarker for pesticide exposure, using data from the self-report questionnaire survey about the presence/absence of depressive symptoms as well as GDS-15 scores. Among exposure-related environmental factors, a potential correlation was assumed between the use of mosquito repellants in summer and a high depression scale score. Additionally, the depression scale scores were higher among male smokers, and a further study addressing this aspect would be meaningful. Also, an analysis of the general health status, a well-known influential factor for depression, revealed a statistically significant association between the two variables, consistent with the results of previous studies. This is assumed to be quantitative evidence for the effects of promoting physical health on mental health among older rural populations. As the present study had a cross-sectional design and a relatively small sample size, further research is needed in the form of a panel study or follow-up study.

We further investigated national data regarding the prevalence of depression in older populations. According to data published by Statistics Korea, the prevalence of depression in the older population in 2013 ranged between $12.4 \%$ and $16.1 \%$ (60 to 69 years: $12.4 \%, \geq 70$ years: $16.1 \%)$, indicating a slight decrease relative to the preceding year ( 60 to 69 years: $15.1 \%, \geq 70$ years: $17.9 \%$ ) and maintenance of a constant level of $15 \%$ since 2010 [23]. According to the results of a study conducted by Noh et al. [24], an analysis of the first-year raw data from the fifth Korea National Health and Nutrition Examination Survey in 2010 revealed a prevalence of depression among female aged 65 to 74 years of $23.36 \%$; this rate was higher than that of other age ranges and approximately 2.6 times higher than that of their male counterparts (8.85\%). These two prevalence-related findings were not consistent with each other because of the use of different diagnostic criteria and research approaches. However, all indicate a 2 -fold higher prevalence in female than in male, which is consistent with the results of our study.

On the other hand, the pesticide consumption volume in Korea was 7414 tons in 2010, the second highest among 19 countries surveyed in the same year. A volume of 5047 tons was re- 
ported in 2012, indicating a decreasing tendency [25]. Despite the high pesticide consumption, there is a lack of research regarding the health effects of agricultural chemicals, including pesticides, among rural, older populations. Relevant research is considered necessary, given the various paths through which people can be exposed in everyday life to agricultural chemicals such as mosquito repellents and insecticides.

A limitation of this study that should be mentioned is that although our older population sample ( $\geq 60$ years) was representative of the overall population in the rural area in terms of the sex, age, and health insurance status distributions, as mentioned above, the study results lack generalizability because older residents were targeted only in one area. Another limitation is related to the timing of biosample collection. Although 3-PBA, the biomarker related to pesticide exposure, is a fast-acting biomarker, it was harvested in winter when the subjects had no direct contact with pesticides. A follow-up study, which may be conducted during a season in which pesticides are often used, is expected to contribute more pertinent results.

Despite these limitations, the academic significance of this study lies in its nature as the nationwide first study to investigate the association between the level of pesticide exposure using biosamples and the presence/absence of depressive symptoms in an older, rural population.

\section{Acknowledgements}

This study was funded by the National Institute of Environmental Research of the Ministry of Environment in South Korea within the framework of the research project "Research on elderly population exposures to hazardous environmental factors and related health effects."

\section{Conflict of Interest}

The authors have no conflicts of interest with material presented in this paper.

\section{References}

1. United Nations. World population ageing: 1950-2050 [cited 2014 Oct 11]. Available from: http://www.un.org/esa/population/publications/worldageing19502050/.

2. Howe N, Jackson R, Nakashima K. The aging of Korea: demographics and retirement policy in the land of the morning calm; 2007 [cited 2014 Oct 20]. Available from: http://csis.org/files/ media/csis/pubs/070321_gai_agingkorea_eng.pdf.

3. Koenig HG, Cohen HJ, Blazer DG, Pieper C, Meador KG, Shelp F, et al. Religious coping and depression among elderly, hospitalized medically ill male. Am J Psychiatry 1992;149(12):1693-1700.

4. Atreya K, Sitaula BK, Overgaard H, Bajracharya RM, Sharma S. Knowledge, attitude and practices of pesticide use and acetylcholinesterase depression among farm workers in Nepal. Int J Environ Health Res 2012; 22(5):401-415.

5. Jackson J, Antonucci T, Gibson R. Cultural, racial, and ethnic minority influences on aging. In: Birren JE, Schaie KW, editors. Handbook of the psychology of aging. San Diego: Academic Press; 1990, p. 103-123.

6. Avigliano L, Fassiano AV, Medesani DA, Ríosde Molina MC, Rodríguez EM. Effects of glyphosate on growth rate, metabolic rate and energy reserves of early juvenile crayfish, Cherax quadricarinatus M. Bull Environ Contam Toxicol 2014;92(6):631-635.

7. Freire C, Koifman S. Pesticides, depression and suicide: a systematic review of the epidemiological evidence. Int J Hyg Environ Health 2013;216(4):445-460.

8. US Environmental Protection Agency. Pyrethroids and pyrethrins; 2013 [cited 2015 Apr 2]. Available from: http://www.epa.gov/ oppsrrd1/reevaluation/pyrethroids-pyrethrins.html.

9. Barr DB, Olsson AO, Wong LY, Udunka S, Baker SE, Whitehead $\mathrm{RD}$, et al. Urinary concentrations of metabolites of pyrethroid insecticides in the general U.S. population: National Health and Nutrition Examination Survey 1999-2002. Environ Health Perspect 2010;118(6):742-748.

10. Beyond Pesticides. Pyrethroids/pyrethrins [cited 2014 Oct 22]. Available from: http://www.beyondpesticides.org/infoservices/ pesticidefactsheets/toxic/pyrethroid.php.

11. Greenberg SA. The geriatric depression scale (GDS); 2012 [cited 2014 Oct 15]. Available from: http://consultgerirn.org/uploads/ File/trythis/try_this_4.pdf.

12 de Craen AJ, Heeren TJ, Gussekloo J. Accuracy of the 15-item geriatric depression scale (GDS-15) in a community sample of the oldest old. Int J Geriatr Psychiatry 2003;18(1):63-66.

13. Kim J, Ko Y, Lee WJ. Depressive symptoms and severity of acute occupational pesticide poisoning among male farmers. Occup Environ Med 2013;70(5):303-309.

14. World Health Organization. Definition of an older or elderly person [cited 2014 Oct 11]. Available from: http://www.who.int/ healthinfo/survey/ageingdefnolder/en/.

15. Korean Statistical Information Service. Urinary 3-PBA concentration after adjusting for creatinine levels; 2013 [cited $2014 \mathrm{Nov} 15$ ]. Available from: http://kosis.kr/statHtml/statHtml.do?orgId=106\&tblId=DT_1 06T_013427\&vw_cd=\&list_id $=\&$ scrId $=\&$ seqNo $=\&$ lang mode=ko\&obj_var_id=\&itm_id=\&conn_path=K1\&path=Korean).

16. National Institute of Environmental Research. Nationwide general state of multiple exposure to various chemicals; 2012 [cited 2014 Nov 30]. Available from: http://www.nier.go.kr/NIER/EgovMovePageMain.do?linkPage=nier-nf-03\&nId=13571\& Command $=\mathrm{RE}$ $\mathrm{AD}$ (Korean).

17. Beseler C, Stallones L, Hoppin JA, Alavanja MC, Blair A, Keefe T, et al. Depression and pesticide exposures in female spouses of licensed pesticide applicators in the agricultural health study cohort. J Occup Environ Med 2006;48(10):1005-1013.

18. Beseler CL, Stallones L. A cohort study of pesticide poisoning and depression in Colorado farm residents. Ann Epidemiol 2008;18 (10):768-774. 
19. Mackenzie Ross SJ, Brewin CR, Curran HV, Furlong CE, Abraham-Smith KM, Harrison V. Neuropsychological and psychiatric functioning in sheep farmers exposed to low levels of organophosphate pesticides. Neurotoxicol Teratol 2010;32(4):452-459.

20. Sanne B, Mykletun A, Moen BE, Dahl AA, Tell GS. Farmers are at risk for anxiety and depression: the Hordaland Health Study. Occup Med (Lond) 2004;54(2):92-100.

21. Lee HJ, Kahng SK, Lee JY. The effects of socioeconomic position and health behavior on geriatric depressive symptoms. J Korean Gerontol Soc 2008;28(4):1129-1145 (Korean).

22. Kim J, Ko Y. Lee WJ. Depressive symptoms and severity of acute occupational pesticide poisoning among male farmers. Occup En- viron Med 2013;70(5):303-309.

23. Korean Statistical Information Service. Depression experience rate trend [cited 2015 Mar 6]. Available from: http://kosis.kr/statHt$\mathrm{ml} /$ statHtml.do?orgId=117\&tblId=DT_11702_N062\&conn path=I3 (Korean).

24. Noh HY, Lee SY. Policy issues and directions for a rapid increase in suicides in Korea. Health Welf Policy Forum 2013;200:7-18 (Korean).

25. Korean Statistical Information Service. Amount of pesticide use [cited 2015 Mar 6]. Available from: http://kosis.kr/statHtml/ statHtml.do?orgId=101\&tblId=DT_2KAAF05\&conn_path=I3 (Korean). 